The $B D J$ News section accepts items that include general news, latest research and diary events that interest our readers. Press releases or articles may be edited, and should include a colour photograph if possible. Please direct your correspondence to the News Editor, Arveen Bajaj at the $B D J$, The Macmillan Building, 4 Crinan Street, London N19XW or by email to bdj@bda.org

\section{Increased support for applicants}

Increased support is being made available for dental practices aiming to achieve a prestigious quality award.

Practices working towards membership of the British Dental Association's Good Practice Scheme will benefit from enhanced telephone support and workshops for practice managers. This support will give applicants more help in developing their portfolio, ensuring they meet the 24 month application window for membership of the Scheme.

A new version of the self assessment programme for the Good Practice Scheme will ensure that applying practices are up-to-date with the latest requirements, including ten new requirements drawn from the guidance of organisations including the General Dental Council, the Department of Health, the Health and Safety Executive and the Environment Agency. The programme's model policies and procedures have also been revised, taking into account changes to child protection guidance.

For more information contact 020 $75634597 / 8$ or email goodpractice @bda.org.

\title{
Volunteers needed in Indonesia
}

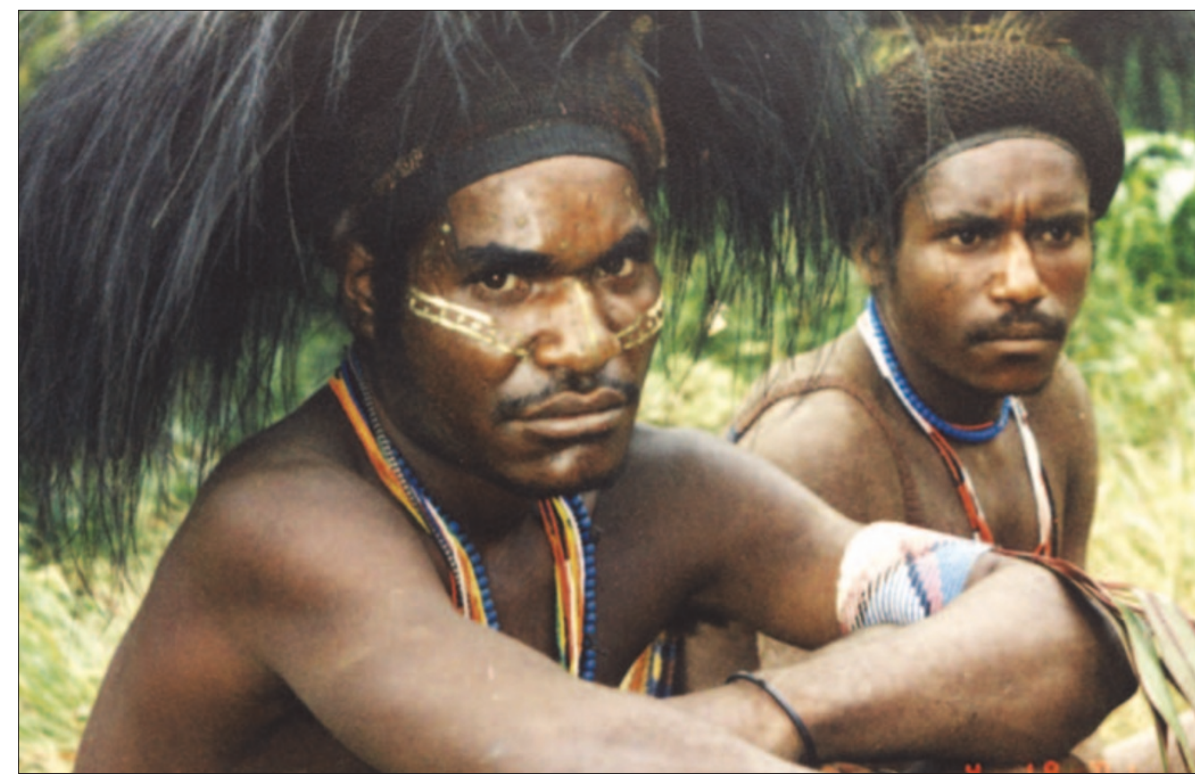

A charitable organisation is looking for a volunteer dentist to go to the remote jungles of Papua, Indonesia this year to carry out emergency dental care. Most of the work will involve tooth extractions on rotten teeth with long roots as well as any other work that can be carried out in extremely primitive conditions.

The trip is planned for around the last week in November and first week in December this year, dependent on visas, and will last for around two to three weeks.

Anyone who would be interested in taking part, or that could donate instruments, drugs and sundry items can contact Teresa Taras on 07973265611 or by email, swelteruk@aol.com. Pictured above, tribesmen of Papua.

\section{Winning BDJ front cover}

An up and coming artist has been selected by $B D J$ readers to design twelve different front covers for the BDJ's volume 202 cover series.

The $B D J$ previously commissioned a number of 'new' artists to create the covers for its landmark volume 200 series, with the brief of creating a cover that represented the joint themes of 200 and oral health/dentistry.

Joseph Dixon, a young artist from East
London designed the cover for BDJ 200:6 which got the most votes from readers, and will now be commissioned to create the covers for volume 202 .

As an added thank you for those who voted, the $B D J$ gave a magnum bottle of Laurent Perrier champagne to the responder of the first reply drawn from the total entries received.

The winner of the draw was Dr David Saunders from Southampton.

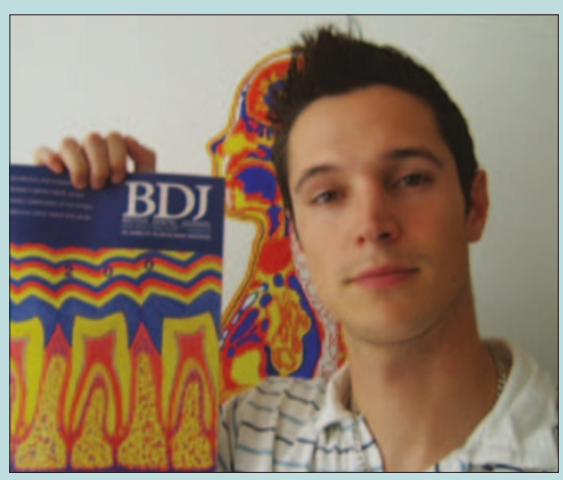

Joe Dixon with the winning cover 


\section{Breakthrough in inflammation research}

Researchers have created a mouse that exhibits reduced inflammation according to a paper published in The Proceedings of the National Academy of Science (PNAS), recently. Researchers from Boston University School of Dental Medicine found that the transcription factor LITAF (Lipopolysaccharide [LPS]-Induced TNF-Alpha Factor) controls inflammation through a completely different pathway than the better known and studied NF-kB transcriptional regulator.

They created a mouse lacking the gene that encodes for the LITAF protein and found that several cytokines were induced at lower levels in the LITAF-deficient mice compared with the levels observed in the LITAF-positive control mice. Specifically, the deficient mice were more resistant to

\section{LPS-induced lethality.}

"The generation of the macrophagespecific LITAF-deficient animals opens new opportunities for assessing the role of LITAF in inflammation in hopes of designing anti-LITAF drugs for major inflammatory diseases," says Dr Salomon Amar of Boston University, the lead author of the paper. Dr Amar discovered the LITAF transcription factor in 1999.

Researchers are now working on whether other molecules work in synergy with LITAF. The paper is entitled, Macrophage-specific LITAF-deficient mice express reduced LPS-induced cytokine profiling: further evidence for LITAFdependent LPS signaling pathways, by Xiaoren Tang, Daniel Metzger, Susan E. Leeman, and Salomon Amar.

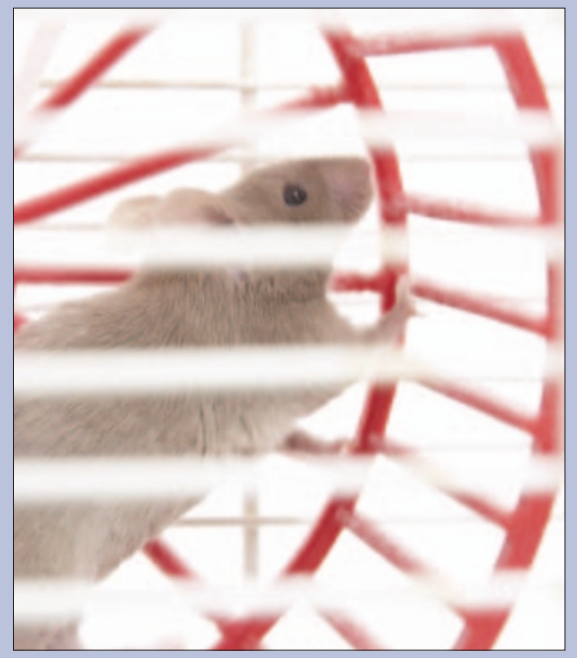

Researchers created a mouse lacking the key inflammation gene

\section{Tackling kids' tooth decay}

A scheme to encourage families with young children in disadvantaged areas to get into the habit of brushing their children's teeth regularly with fluoride toothpaste was launched by Health Minster Rosie Winterton at the Appleby health centre in Newham recently - an area with one of the highest oral health needs in the country.

The Brushing for Life initiative will see health visitors and health care professionals with appropriate training distribute free 'Brushing for Life' packs containing a Colgate toothpaste, toothbrush and a leaf-

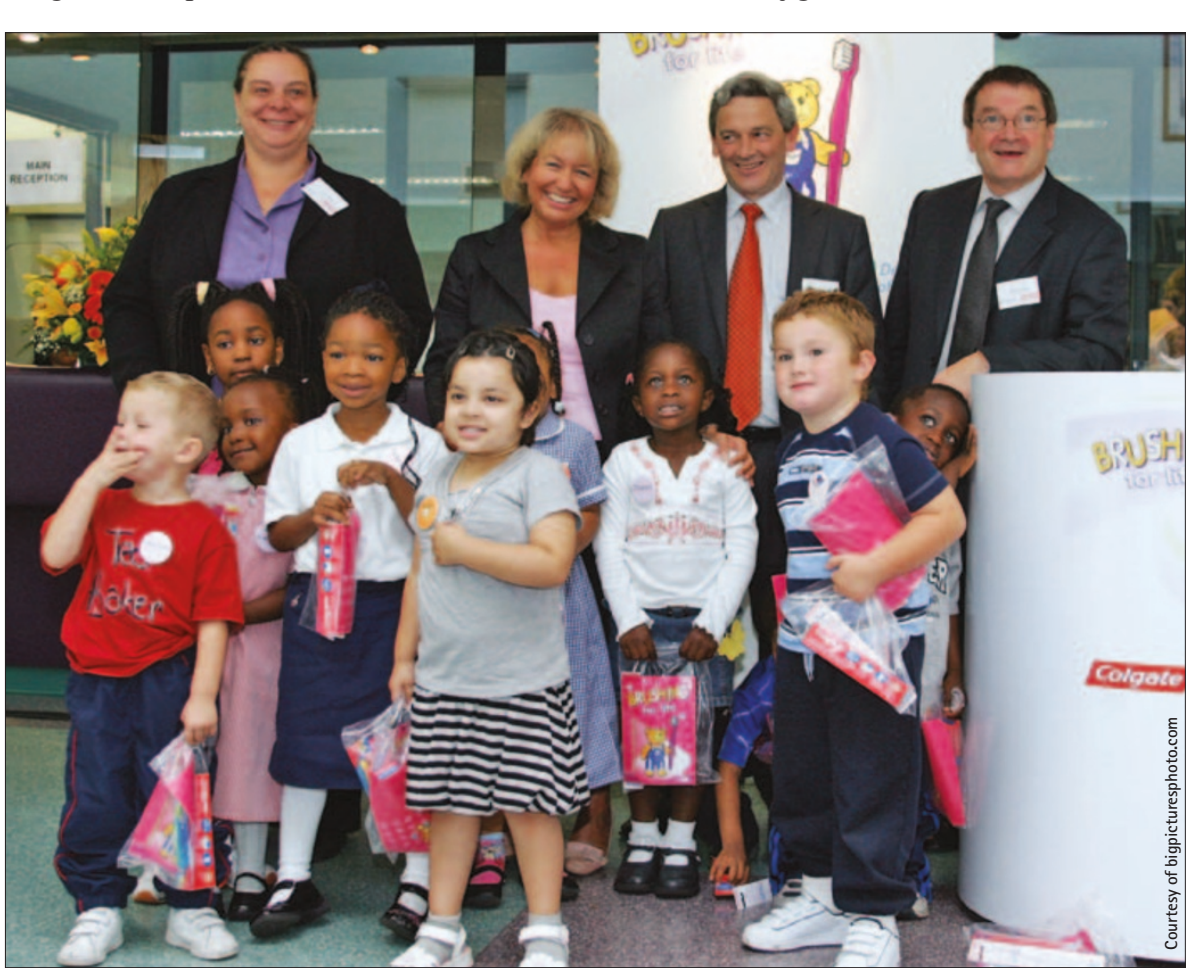

let on oral hygiene to families with young children when they are visiting their local health centre. The staff also give advice to the families' parents on the care of their child's teeth, ensuring that oral health is part of general health promotion.

Launching the Brushing for Life initiative, Rosie Winterton said, "Thanks to the introduction of fluoride toothpaste and better oral health education, there have been major improvements in oral health. However, behaviour we learn as children on diet and dental hygiene lasts all our lives."

\section{Salivary melatonin link to periodontal disease}

Salivary melatonin may play an important role in maintaining periodontal health, according to a new study published in the Journal of Periodontology. The study attempts to examine the influence of salivary melatonin on periodontal disease and researchers found that melatonin, a hormone created by the pineal gland, may be able to protect the oral cavity against free radicals produced by inflammatory diseases. Melatonin has strong antioxidant effects that can protect cells against inflammatory processes and oxidative damage and melatonin supplements are commonly promoted to ease jet lag and hasten sleep. Thirty-seven patients with different degrees of periodontal disease were studied. The mean age was 55 and included 21 females and 16 males. All participants underwent a medical and dental examination. Salivary and plasma melatonin levels and CPI status were collected from each patient.

"Patients with higher salivary and melatonin ratios had lower community periodontal index (CPI). CPI is the score used to assess periodontal status," said Pablo Galindo, from the Department of Oral Surgery, School of Dentistry, University of Granada, Spain. "This finding suggests that the melatonin may fight against infection and inflammation possibly due to its antioxidant, anti-aging and immunoenhancing ability." 


\section{Urgent attention needed for Filipino children}

Oral health of school children in the Philippines needs urgent attention according to the results of a national oral health survey presented during a conference in Manila.

Results of the survey revealed that $97.1 \%$ of six-year-old children suffer from dental decay and $84.7 \%$ even show symptoms of dental infection. The care index was $0.0 \%$ in both age groups, indicating that no treatment has been performed among the 4,050 examined children representing the twelve million public elementary school population of the Philippines. In addition, 20\% of the six-year-old and 16\% of the twelveyear-old children reported problems such as pain or discomfort in their mouth at the time they were questioned.

"The results of the survey show the huge burden of disease among Filipino school children. In addition, we found that more than 25\% of the children are underweight and the majority of children suffer from skin disease, parasites and other signs of generally poor hygiene," said Dr Bella Monse Schneider, Consultant to the Department of Education and Coordinator of the survey that was funded by the German Development Agency INWENT.

During the conference in Manila, national and international experts presented examples and policies that could help address the huge problem of dental decay rates, which rank among the

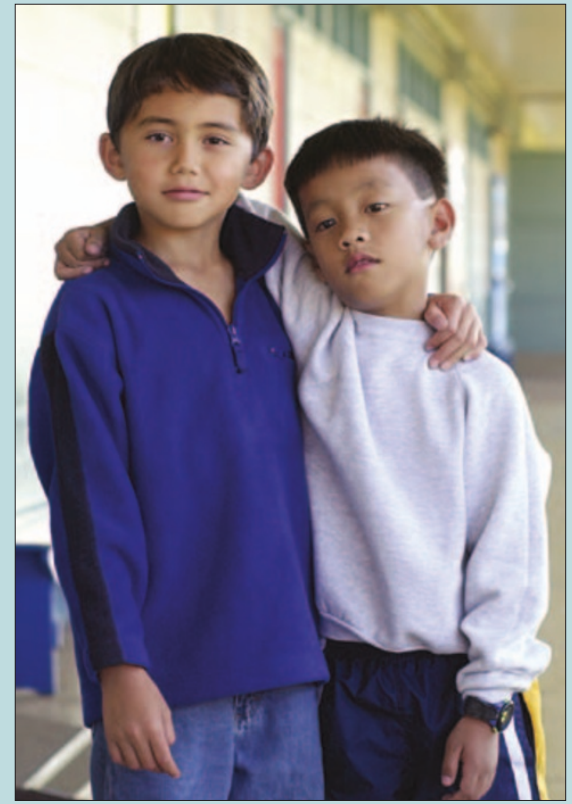

highest in the region and worldwide. "The results of the survey are a wake-up call for all stakeholders to rethink current approaches and strategies," said Dr Habib Benzian, FDI Development and Public Health Manager, representing the FDI at the conference.

The President of the Philippine Dental Association, Dr Leticia Santos, said that the dental profession is keen to cooperate with the government and other stakeholders in order to improve the situation. Within the framework of the global Live. Learn.Laugh. Programme, the FDI and the Philippine Dental Association will support, during the next three years, a pilot project focussing on innovative approaches to improve oral health of Filipino children.

\section{Core subjects for dentists' CPD}

The General Dental Council (GDC) is recommending that all dentists carry out continuing professional development (CPD) in core recommended subjects from the beginning of their next CPD cycle. It says this recommendation follows a public consultation earlier this year.

The recommended core subjects and suggested minimum number of verifiable hours per CPD cycle that dentists spend on them are medical emergencies (at least 10 hours per CPD cycle), disinfection and decontamination (at least 5 hours per CPD cycle) and radiography and radiation protection (at least 5 hours per CPD cycle).

In addition, the GDC recommends that dentists working in a clinical environment carry out CPD (verifiable or general) to make sure that they are up to date in legal and ethical issues and handling complaints. It also recommends that all dentists use a personal development plan so that patients and dentists themselves benefit as much as possible from their CPD. The GDC is producing new guidance for dentists about CPD which will be sent to all dentists in October this year.

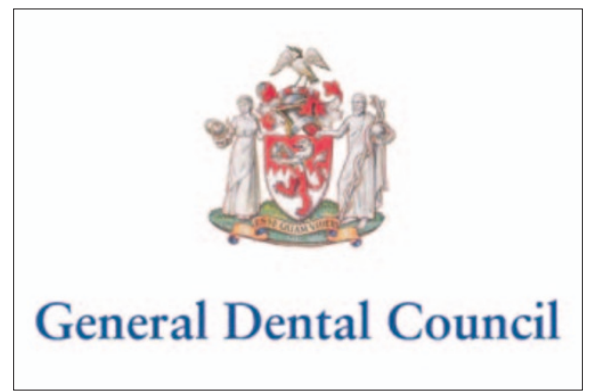




\section{DIARY}

October

Community Dental Services Group Annual Presidential and Scientific meeting Venue: Marriott Forest of Arden Hotel, Birmingham

Date: 12-13 October 2006

www.bda-events.org

The American Dental Association (ADA) 147th ADA Annual Scientific Session and Marketplace Exhibition

Venue: Mandalay Bay Resort and

Convention Center, Las Vegas

Date: 16-19 October 2006

www.ada.org

Hospitals Group Annual Presidential and Scientific meeting

Venue: Portmeirion, North Wales

Date: 26-27 October 2006

www.bda-events.org

November

BDA events - A clinical guide to

periodontology

Venue: Marriott Hotel Regent's Park, London

Date: 3 November 2006

www.bda-events.org

British Academy of Cosmetic Dentistry's

(BACD) 2nd Annual Conference

Venue: Britannia International Hotel, London

Date: 16-17-18 November 2006

Email: info@bacd.com

www.bacd.com

The 2006 ADF Conference and Trade Exhibition

Date: 21-25 November 2006

Venue: Palais des Congrès de Paris, France

Email: adf@adf.asso.fr

www.adfcongres.com

Moving to Private Practice - practical considerations

Date: November 242006

Venue: Macrobert Arts Centre, Stirling,

Scotland

www.bda-events.org

Health Protection Agency: Laser and IPL Sources Safety Training for Medical and Cosmetic Applications

Venue: HPA Radiation Protection Division, Leeds

Date: 28 November 2006

Telephone: 01132679041

www.hpa.org.uk

\section{Amazonian dental adventure}

A charity is looking for volunteer dentists to help some of the poorest and most deprived people in the world. The Vine Trust is an international interdenominational charity with a vision to see communities transformed and works to bring opportunity, health and hope to disadvantaged communities and marginalised people with a particular concern for vulnerable children.

The charity's two boats, the Amazon Hope and the Amazon Hope 2, bought and refurbished in Britain, aim to meet the health needs of the people living in the remote villages on the banks of three tributaries of the Amazon in Peru.

Every month a medical team (including one or two dentists) from the USA or UK arrives in Iquitos to spend nine days working on one of these boats. They have a dental surgery, medical areas and a pharmacy. All together $25-30$ people live, eat and work on the boat for the nine days, the visiting team working alongside the Peruvian medical team providing care for up to 2,000 patients (including 200400 dental patients).

One volunteer who has recently returned from a trip is Shona Mason, Clinical Lecturer in Removable Prosthodontics, Dental School, University of Dundee.

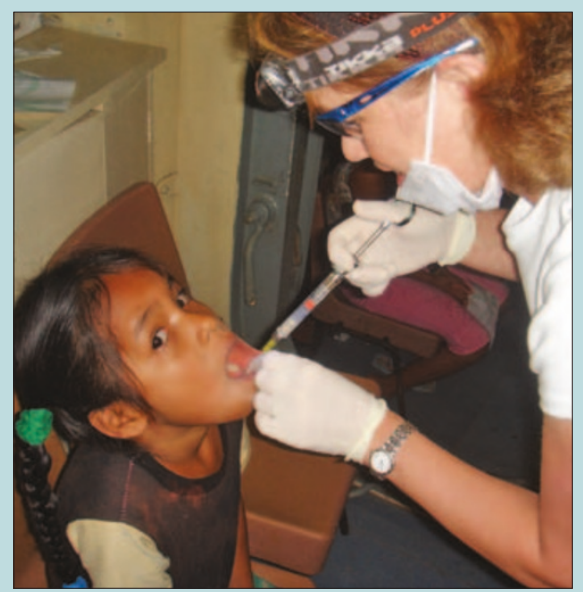

Volunteer Shona Mason treats a young patient

According to Mrs Mason, the majority of the dental work is extractions but already the proportion of simple restorative work being carried out is increasing as the villages start to get regular three monthly visits from one of the boats. "The patients are wonderful - and you do not need to speak the same language to understand the gratitude of someone who has just been relieved of the tooth that has tortured them for months," she says. For more information visit www.vinetrust.org.

\section{Dentists increase earnings from private work}

Dentists who worked to the General Dental Services (GDS) contract earned more from private work than from the NHS during 2004/05, according to new figures on dentists' earnings and expenses published today by The Information Centre for health and social care.

A study of earnings and expenses in 2004/05 revealed that, overall, dentists in Great Britain working under GDS earned 48 per cent of their gross income from NHS work compared with 54 per cent the previous year.

Dentists who are practice owners received an average annual income of $£ 105,000$, after expenses have been deducted, from both NHS and private sources, while dentists who use facilities within another dentist's practice earned less; on average $£ 57,000$.

Dentists who practise alone earned an average of $£ 86,000$, with those that were most committed to the NHS earning $£ 84,000$ and those that were less committed earning $£ 89,000$ on average. An additional study, for the year 2005/06, covers NHS income only. This shows the wide range of income levels from this source of work, with some dentists earning less than $£ 5,000$ from the NHS and others earning over £300,000 (before expenses are deducted).

The figures relating to GDS in both studies refer to all full-time and part-time dentists' NHS earnings, under the GDS arrangements in operation up to $31 \mathrm{March}$, 2006. These were complex and based on a mix of fees paid for registered patients, for treatment of patients, incentive payments (such as commitment payments) and other exceptional payments (such as maternity and long-term sickness payments).

The new contract introduced on 1 April 2006 brought in a different way of paying dental practitioners for their NHS work and a simpler system of payments, with an emphasis on encouraging more preventative work.

For a copy of the report see www. ic.nhs.uk/pubs/dentalearn and www.ic.nhs. uk/pubs/gdspay. 